\section{EPIDEMIOLOGY OF BARTONELLOSIS}

TF any biologist requires a problem which will 1 exercise to the full his patience and experimental skill, he could get it from the monograph "Infoctious Anæmias due to Bartonella and Related Red Cell Parasites", by David Weinman (Trans. Amer. Phil. Soc., Philadelphia, New Series, 33, Part 3, $243-350$; 1944). Weinman was parasitologist to the Harvard Expedition to Peru in 1937, which finally established the fact that Bartonella bacilliformis is the cause of both Oroya fever and Verruga peruviana (Verruca peruviana, Verruga peruana), both of which are sometimes called Carrión's disease. Carrión, one of the pioneers of the study of these South American diseases, died of Oroya fever after inoculating himself with verruga material.

As Prof. Tyzzer says in his preface to this monograph, the symptoms of these two diseases are so different that it is not surprising that they were, until comparatively recently, considered to be due to different organisms. The main symptoms of Oroya fever are fever, marked pain in the head, joints and bones and a rapidly developing anæmia. If the patient does not die in a few weeks, a verrucous stage may follow. The mortality is 40 per cent or higher. Verruga peruviana is a milder infectious disease in which superficial and deep nodules appear. The superficial ones resemble warts and are about the size and colour of cranberries when they are mature; the subcutaneous ones are larger, less 'numerous and often erode the skin surface. These axuptions last from one to twelve months and then disappear. Mortality is low. Latent infections with Bartonella bacilliformis may occur without symptoms. It is now known that both diseases are due to the single species of Bartonella-Bartonella bacilliformiswhich was formerly classed among the Protozoa, but is now classified by Tyzzer, Weinman and others as a flagellated bacillus.

The two diseases caused by this organism are both confined, at present, to a restricted area of South America, namely, to a narrow strip of the Andes in Peru to foci in the south-west of Ecuador and to the neighbourhood of the city of Pasto in Colombia. Central American foci in Honduras and Guatemala have been suspected, but have not been proved. Weinman points out, however, that human bartonellosis appears to be spreading in its epidemic form. In animals the related genera Hamobartonella and Eperythrozoon, which have been, for reasons discussed by Weinman in this monograph, removed from the genus Bartonella, are widely distributed and may be present in laboratory animals used for studies of the blood or reticulo-endothelial system or for nutritional and other problems; they may profoundly affect the results of these studies. The comparative study of animal bartonellosis may, Weinman thinks, illuminate the etiology, pathogenesis and treatment of blood diseases. This study has already revealed that the spleen has an important immunological function in animals infected with Bartonella. It maintains an equilibrium between certain of these parasites and their hosts, which is so perfect that infection may never be apparent unless splenectomy is performed; and the study of this function of the spleen may give us new information about the relation of the spleen to immunity. We are here reminded of the work of J. E. Larsh, jun. (Amer. J. Hyg., 39, 133 ; 1944 ; and Trop. Dis. Bull., 41, 765; 1944) on the increased susceptibility of mice not infected with
Bartonella to infestations with the cestode Hymenolepis nana var. fraterna, when the whole spleen (that is, a large part of the reticulo-endothelial system) is removed.

Historically the cutaneous form of human bartonellosis, Verruga peruviana (Verruga peruana), was known to the pre-Inca inhabitants of Peru. Among the illustrations of operations and diseases found on ancient pottery ('huacos') "pertaining to the Chimu civilization", Verruga peruviana has been identified. When the Spaniards arrived, they found that Verruge peruviana was already distinguished in the Keshua language from the common wart and other diseases, and the very first group of conquering Spaniards suffered from it. Less appears to be known about the history of the anæmic form of human bartonellosis (Oroya fever). A serious epidemic of it in 1870 in workers building a railway from Lima to Oroya caused 7,000 deaths, and this and later epidemics led to the popular saying that "every crosstie in the railroad represented a human life". The nature of Oroya fever was not clearly known until Carrión, who was dissatisfied with the existing knowledge of Verruga peruviana, decided to inoculate himself with verruga material. He developed Oroya fever and died of it on October 5, 1885. It was not until 1905 that Barton described bodies in the blood which were, he claimed, living organisms and the cause of Oroya fever. His claims were not accepted until the 1913 Harvard Expedition to Peru confirmed Barton's findings and gave the name Bartonella bacilliformis to the bodies which he had described. This Expedition made great contributions to our knowledge of the disease. But its etiology remained obscure until Noguchi and Battistini cultivated $B$. bacilliformis. The 1937 Harvard Expedition to Peru finally established the fact that $B$. bacilliformis causes both Oroya fever and Verruga peruviana.

$B$. bacilliformis is extremely polymorphous, and its taxonomy, microscopical appearance, cultivation and behaviour in experimental animals are fully described. by Weinman. The symptoms of the various forms of the two diseases which it causes are also described in detail. The section on epidemiology and transmission by sandflies is valuable. Phlebotomus verru. carum seems to be the most important vector of the three species of Phlebotomus occurring in those areas of Peru in which bartonellosis is endemic ( $P$. verrucarum, $P$. noguchii, $P$. peruensis $)$. The four other Peruvian species of Phlebotomus have not yet been incriminated; and no other blood-sucking arthropod has been shown to be naturally infected with Bartonella. Infection by contact does not occur in ordinary circumstances. The disease has, however, been reported as a new one in Colombia since 1935, and none of the Peruvian sandflies has yet been collected in Colombia. This suggests that $B$. bacilliformis was introduced into Colombia and then became estab. lished in the Colombian sandflies, rather than that Peruvian infected sandflies became acclimatized in Colombia (as, for example, African Anopheles gambice became established in Brazil in 1939 and caused there one of the most devastating epidemics of malaria known to history (see Nature, 153, 765; May 20, 1944)). If this is so, the question arises whether other species of Phlebotomus could become vectors of $B$. bacilliformis. This question has not been studied experimentally. It is important, because sandflies which bite man are widely distributed throughout the world in tropical and temperate countries (cf. the part they play in transmitting to 
man the cause of human cutaneous leishmaniasis (Leishmania tropica) in the Gerbils and Sousliks of the deserts of middle Asia, described in a review of Russian work on this question by C. A. Hoare (Trop. Dis. Bull., 41, 331 ; 1944)). Modern rapid methods of transport could either carry the sandflies which transmit Bartonella or infected human beings to an area inhabited by uninfected sandflies.

Two alleged cases of congenital transmission of Bartonella in man are reported by Weinman, and the factors affecting susceptibility and resistance to the infection are discussed. Man is the only important known source of $B$. bacilliformis, and Phlebotomus the only other animal known to be naturally infected. There is, however, some evidence that dogs may be naturally infected sometimes. The suggestion that domestic animals, lizards, rats and some plants may be reservoirs of the infection has not been confirmed. Weinman discusses at length the immunology, treatment and control of the infection, but these complex questions cannot be discussed here. Treatment of Oroya fever is the most important, because of its high mortality, but the study of it is handicapped by our inability to produce the syndrome at will in experimental animals.

In Chapter 2 Weinman discusses the genus Hcemobartonella, created by Tyzzer and Weinman in 1939, to include Bartonella-like organisms which do not multiply outside the blood and do not produce skin eruptions, whereas human $B$. bacilliformis develops in fixed tissue cells and causes skin eruptions. $H$. muris, the type species, is a widely distributed parasite of the albino rat, in which it exists as a latent infection and causes anæmia. It is transmitted by rat lice and fleas. It is infectious for albino mice, the rabbit and some other rodents. It can be eradicated by neoarsphenamine and other organic arsenicals. Weinman describes fully the other species, of which twenty-one have been named. Those most clearly established are in albino rats and mice and some other rodents, in voles, guinea pigs, oxen, buffalo and dogs. Other forms of Homobartonella not of specific rank have been found in the wild rat, dormouse, opossum, hamster, deermouse and squirrel. Organisms having some resemblance to Hoemobartonella have been recorded from the bat, monkey, ant-eater, rat and dormouse and from the tortoise, frog, lizard, gecko, lamprey, tench and pike.

Chapter 3 deals with Eperythrozoon. Species of this genus are blood parasites with some resemblance to Bartonella and Homobartonella, and they cause anæmia in various vertebrates. The infection, which at first causes symptoms, becomes latent, and removal of the spleen causes relapses. These organisms have not yet been cultivated in vitro, but animals can be infected by inoculation of infected blood. Their transmission by arthropods is known and they respond to therapy with organic arsenicals, so that they are regarded as being living organisms. They occur in white mice (E. coccoides, transmitted by the louse, Polyplax serrata, and possibly by other means) ; in dwarf mice and voles (E. dispar); in sheep ( $E$. ovis, the method of transmission is not known) and in cattle ( $E$. wenyoni, the method of transmission is not known). Other so-called species require confirmation. The single case in which infection of man (a child) with Eperythrozoon was suspected is discussed by Weinman.

Chapter 4 discusses the public health aspects of bartonellosis. Its importance is shown by the fact that although the epidemic of 1870 in Peru involved a very small region, some 7,000 people died; and in Colombia more recently 4,000 deaths have been attributed to bartonellosis in one year (1938). The disease is, so far as we know, restricted to Peru, Colombia and Ecuador, and is irregularly distributed in a long, narrow area of the Andes, 1,000 miles long by about 100 miles wide, in which it occurs at moderate altitudes, near water and most often in narrow valleys; but it is probable that its distribution is incompletely known.

Man is both the victim and reservoir of Bartonella bacilliformis and no other animal naturally infected with this species is known, except the sandfly vector. Weinman discusses fully the epidemiological evidence for this. Further knowledge of the insect vector is required, because most of our knowledge about it has been worked out in Peru only. The nocturnal biting activity of the sandfly explains why the disease is chiefly contracted at night, and this biological fact has been used for control. Workmen repairing a railway bridge over the Rimac River were, for example, removed by train from the bridge in time to be outside the endemic zone before nightfall. Phlebotomus-proof buildings would be equally effective, and when Shannon lived for months in one of these in an endemic area, he did not become infected; but the expense of providing them for everyone would be great. Repellents applied to the body and insecticides are said to help protection. Other measures aim at reduction of the numbers of the sandflies by destruction of the day-time hiding places of the adults in dark places; but lack of knowledge of the biology of the immature stages handicaps this kind of control. The adults are not vigorous fliers and probably do not get very far from the places where they emerge. The fact that endemic foci of the disease are bounded by upper and lower limits of altitude, which are often quite sharply defined, requires further explanation.

\section{G. LAPAGE.}

\section{SCIENTIFIC AND INDUSTRIAL RESEARCH IN NEW ZEALAND}

$7 \mathrm{HE}$ eighteenth annual report of the Department 1 of Scientific and Industrial Research, New Zealand, covering the year 1943-44, includes the Minister's statement, the Secretary's report, reports of the research committees of the Council, and on research work at the Canterbury and Massey Agricultural Colleges, as well as on the Dominion Laboratory, Observatory, Physical Laboratory, Magnetic Observatory, Geological Survey and Meteorological Branch.

Under the Building Research Committee, investigations have been continued by the Entomology Division of the Plant Research Bureau into the biology of the two native termites, and in co-operation with the Plant Diseases Division investigations were undertaken into the biology of Anodium punctatum, including the factors controlling oviposition and the influence of seasoning of both kiln- and air-dried sapwood against attack, with the view of securing data on the best method of treating various timbers as a protection against borer attack. The State Advances Corporation has continued its work on field investigations of timber-infesting insects and fungi, and field application of termite control and on 